\title{
Aurora Kinase A expression predicts platinum-resistance and adverse outcome in high-grade serous ovarian carcinoma patients
}

Chiara Mignogna ${ }^{1 *}$, Nicoletta Staropoli $i^{2^{*}}$, Cirino Botta ${ }^{3}$, Carmela De Marco ${ }^{4}$, Antonia Rizzuto ${ }^{5}$, Michele Morelli ${ }^{4}$, Annalisa Di Cello ${ }^{4}$, Renato Franco ${ }^{6}$, Caterina Camastra', Ivan Presta ${ }^{1}$, Natalia Malara', Angela Salvino ${ }^{2}$, Pierfrancesco Tassone ${ }^{3}$, Pierosandro Tagliaferri ${ }^{2}$, Tullio Barni ${ }^{4}$, Giuseppe Donato ${ }^{1}$ and Anna Di Vito ${ }^{4}$

\begin{abstract}
High-Grade Serous Ovarian Carcinoma (HGSOC) is the predominant histotype of epithelial ovarian cancer (EOC), characterized by advanced stage at diagnosis, frequent TP53 mutation, rapid progression, and high responsiveness to platinum-based-chemotherapy. To date, standard first-line-chemotherapy in advanced EOC includes platinum salts and paclitaxel with or without bevacizumab. The major prognostic factor is the response duration from the end of the platinum-based treatment (platinum-free interval) and about 10-0\% of EOC patients bear a platinum-refractory disease or develop early resistance (platinum-free interval shorter than 6 months). On these bases, a careful selection of patients who could benefit from chemotherapy is recommended to avoid unnecessary side effects and for a better disease outcome. In this retrospective study, an immunohistochemical evaluation of Aurora Kinase A (AURKA) was performed on 41 cases of HGSOC according to platinum-status. Taking into account the number and intensity of AURKA positive cells we built a predictive score able to discriminate with high accuracy platinum-sensitive patients from platinum-resistant patients $(p<0.001)$. Furthermore, we observed that AURKA overexpression correlates to worse overall survival $(p=0.001$; HR 0.14). We here suggest AURKA as new effective tool to predict the biological behavior of HGSOC. Particularly, our results indicate that AURKA has a role both as predictor of platinum-resistance and as prognostic factor, that deserves further investigation in prospective clinical trials. Indeed, in the era of personalized medicine, AURKA could assist the clinicians in selecting the best treatment and represent, at the same time, a promising new therapeutic target in EOC treatment.
\end{abstract}

Keywords: High-grade serous ovarian carcinoma (HGSOC), AURKA, Platinum, Therapy, Prognosis

\footnotetext{
* Correspondence: mignogna@unicz.it; nicolettastaropoli@gmail.com

'Department of Health Science, Pathology Unit, Magna Græcia University of

Catanzaro, Medical School, Viale Europa, 88100 Catanzaro, Italy

${ }^{2}$ Department of Experimental and Clinical Medicine, Medical Oncology,

Magna Græcia University of Catanzaro, Medical School, Viale Europa, 88100

Catanzaro, Italy

Full list of author information is available at the end of the article
} 


\section{Background}

Epithelial ovarian cancer (EOC) represents the 5th leading cause of cancer-related death worldwide [1] with approximately 225.500 new diagnoses per year and a mortality rate greater than $30 \%$ [2]. High-Grade Serous Ovarian Carcinoma (HGSOC) is the most aggressive histotype, and accounts for $60-80 \%$ of all ovarian carcinoma [3, 4]. Particularly, HGSOC is characterized by rapid progression and frequent TP53 mutations [5-7]. Primary treatment for HGSOC includes surgery and platinum/taxane based chemotherapy. However, even though $70-80 \%$ of patients show an initial response to chemotherapy, approximately $25 \%$ relapse within 6 months $[8,9]$.

According to time to relapse after last chemotherapy administration, EOC patients are classified into three platinum-status groups. Patients who experience a recurrence after 6 months are deemed platinum-sensitive (PS) and are good candidates for a platinum rechallenge [10]. Conversely, patients who relapse within 6 months are classified as platinum-resistant (PR), and are candidate to alternative treatment schedules that do not include platinum-derived compounds [11, 12]. Approximately $20 \%$ of all EOC patients belong to this latter group [13]. Lastly, the platinum-refractory group involves patients who experience disease progression during the course of treatment. This is the subgroup with the worse prognosis and includes less than $10 \%$ of HGSOC patients [14].

The molecular basis of platinum-resistance is not yet fully understood and experimental results suggest the involvement of several cellular functions, such as: changes in cellular uptake and efflux of cisplatin, increased biotransformation and detoxification in the liver, loss of apoptotic signaling after DNA damage has occurred, DNA repair or DNA damage tolerance. Specifically, genes previously implicated in EOC pathogenesis such as AURKA1, ERBB3, CDK2, and mTOR, and novel candidates such as BRD4, VRK1 and GALK1, have been shown to be involved in such features, thus becoming potential predictive/prognostic markers in HGSOC [15]. In addition, HDAC4, STAT1, FORL2 and PIK3R1 were over-expressed in resistant cells when compared to sensitive cells, suggesting their functional involvement in platinum-resistance [16].

Recently, a meta-analysis indicated Aurora kinase A (AURKA) as an effective prognosticator in solid tumors patients, including EOC [17]. Accordingly, a number of new AURKA inhibitors, such as ZM447439, Hesperadin, VX-680/MK-0457, AT9283 and AZD1152 are being developed to target malignant tumors and clinical trials are ongoing to investigate their efficacy [18].

Aurora kinases are a family of serine/threonine kinases that play a critical role in the regulation of mitosis, especially in the distribution of genetic material to daughter cells [19]. In particular, AURKA has been extensively investigated for its implication in different neoplasms [20] and it has been identified as a low penetrance tumorsusceptibility-gene in human cancer [21]. Moreover, specific AURKA polymorphisms have been associated with carcinogenesis [22-28], while its overexpression has been described in various types of tumors, including laryngeal, breast, colon, pancreas, ovarian, bladder, liver, and gastric cancers [29]. This condition may derive from gene amplification as well as deregulation of gene expression; in addition, inhibition of protein degradation was also reported [20,30]. The molecular mechanism by which AURKA contributes to tumorigenesis is complex, often implying apoptosis and/or autophagy signaling perturbation. Indeed, AURKA interacts with many tumor suppressor proteins ( $\mathrm{p} 53$, BRCA1, glycogen synthase kinase (GSK)-3b, and c-Myc), thus accounting for significant alteration of their modulatory functions [31-34]. Furthermore, AURKA overexpression seems to occur as an early event in EOC development [35, 36].

On these bases, we investigated the association between the expression of AURKA in HGSOC patients' specimens and clinical outcome, taking into account both response to chemotherapy and survival.

\section{Methods}

Forty-one patients with confirmed diagnosis of HGSOC (mean age: 63.43 years; range: $44-88$ years) consecutively treated in our institution between 2009 and 2015, were enrolled in this study. Eligibility criteria included histological diagnosis of EOC, age $>18$ years old, at least one previous line of treatment including a platinum-based schedule. Patients were grouped as PR (platinum-resistant) and PS (platinum-sensitive) taking into account the classification-system based on the "platinum-free interval", i.e. the time-frame between the end of chemotherapy treatment and recurrence, as previously described.

Surgical specimens were retrieved from the archive files of the Department of Health Sciences, Surgical Pathology Section of the University Magna Græcia of Catanzaro, Italy. Clinical data have been retrieved from medical records of the Gynecologic and Medical Oncology Units of the same Institution. All data were entered into an electronic database.

A detailed clinical follow-up, ranging from 3 to 50 months after surgery (average value: 19.13 months) was available for all patients. Written informed consent was obtained from each patient being studied and all procedures performed in this study were performed for diagnostic purposes, in accordance with the ethical standards of the institutional committee responsible for human experimentation.

Immunohistochemical staining procedures were carried out on formalin-fixed, paraffin-embedded archival cell blocks. For AURKA identification, a three layer biotin-avidin-peroxidase system was utilized. Briefly, 
xylene dewaxed and alcohol-rehydrated serial tissue sections $\left(4 \mu \mathrm{m}\right.$-thick) were treated in EDTA buffer at $98 \mathrm{C}^{\circ}$ for $50 \mathrm{~min}$, according to the antigen retrieval method. Afterwards, endogenous peroxidase activity was blocked with $3 \%$ hydrogen peroxide solution. For the evaluation of AURKA signal, mouse monoclonal anti-Aurora Kinase 2 (clone JLM28, 1:50 dilution; Leica Biosystems, United Kingdom) was applied for $1 \mathrm{~h}$ at RT. Biotinylated secondary antibody and avidin-biotin peroxidase complex were then applied and allowed to react for $30 \mathrm{~min}$ at RT. AURKA signals were visualized after addition of $0.01 \%$ DAB (3, 3'-diaminobenzidine tetrahydrochloride). Nuclear counterstaining was perfomed with hematoxylin.

A semi-quantitative analysis was performed, evaluating both percentage of AURKA-positive cells and staining intensity (intensity and percentage-based approaches), using the score system by Allred et al. [37-39]. A percentagebased approach was used in order to estimate the proportion of positively stained tumor cells (0: none, $1:<1 \%, 2$ : 1-10 \%, 3: 10-33 \% 4: 33-66 \%, 5: 66-100 \%) Fig. 1 (a-f). Average estimated intensity of staining in positive cells was assigned as an intensity score $(0=$ none; $1=$ weak; $2=$ intermediate; 3 = strong) Fig. $2(\mathrm{a}-\mathrm{c})$.

An immunoreactive score ranging from 0 to 8 was defined as the sum of percentage score and intensity score. Negative control sections for immunohistochemistry were processed without primary antibody.

Two investigators performed clinical data collection and statistical analyses independently.
Primary endpoint was response rate (RR) according to platinum response. Secondary endpoint was overall survival (OS) in all patients. A Student's test was used to compare the scores of the two patient groups. Kaplan Meier curves and Log Rank test were used to describe and evaluate the effect of several variables on outcome. All tests were considered statistically significant when the p-value was $<0.05$. The relative hazard ratios (HR) with $95 \%$ confidence intervals (95 \% CIs) were calculated using SPSS (version 19) statistical package and Graphpad PRISMA (version 6.0).

\section{Results}

Clinical and pathological parameters of patients and immunohistochemical findings are detailed in Table 1. To verify the reliability of the sample, we evaluated if patients with a platinum-sensitive disease experienced the longest survival. As reported in Additional file 1: Figure S1, according to published literature, patients in the PS group presented the best outcome (50 versus 14 months, $p<$ 0.0001) thus confirming the reliability of the sample. Subsequently, we confirmed the original diagnosis of HGSOC for all cases examined. Two cases were stage IIA, 1 case stage IIB, 4 cases stage IIC, 1 case stage IIIA, 7 cases stage IIIB, 16 cases stage IIIC and 10 cases stage IV tumours according to AJCC guidelines.

The expression of AURKA in neoplastic cells, using the specific score system, was comprised between 0 and

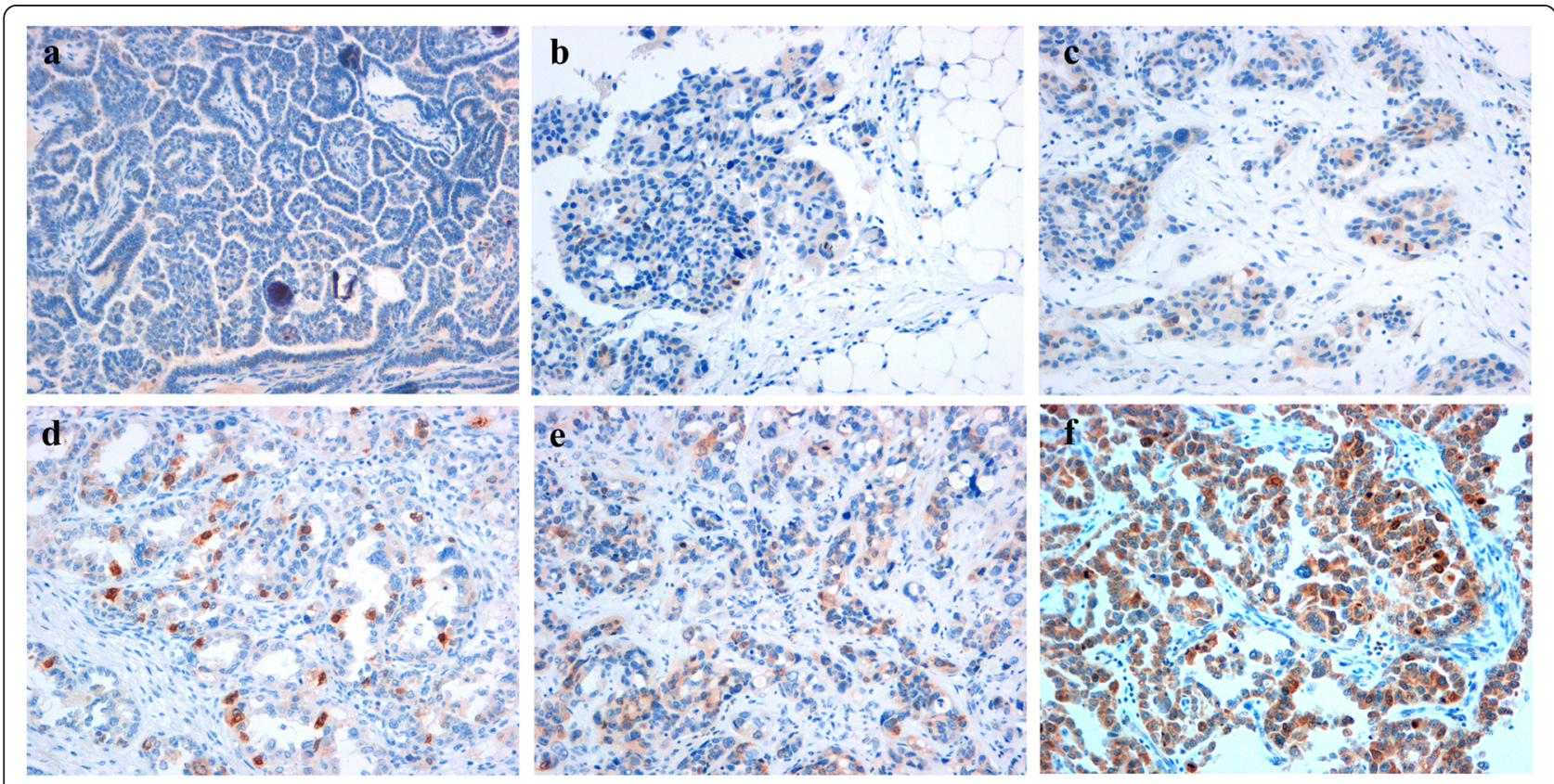

Fig. 1 Immunohistochemical analysis of AURKA in surgical specimens of HGSOC (percentage-based approach). The panel shows a proportion score assigned on the basis of the percentage of AURKA positive tumor cells. 0: no AURKA-positive cells (a), 1:<1 \% (b), 2: 1-10 \% (c), 3: 10-33 \% (d) 4: 33-66 \% (e), 5: 66-100\% (f). Magnification 100x (a), 200x (b-f) 


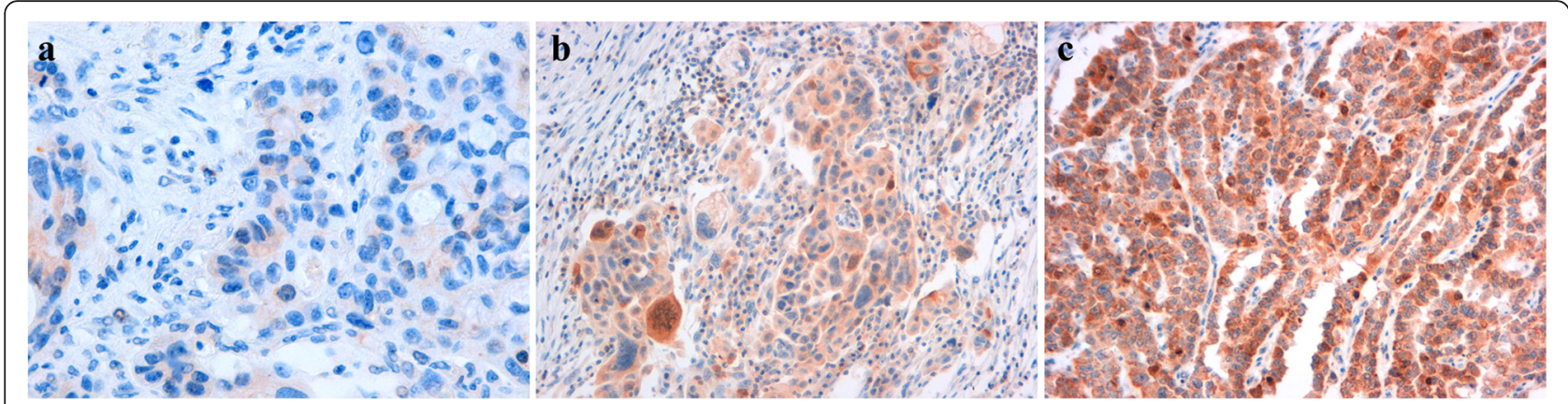

Fig. 2 Immunohistochemical analysis of AURKA in surgical specimens of HGSOC (intensity-based approach). The panel shows three examples of different intensity score value. 1 = weak (a); 2 = intermediate (b); 3 = strong (c) Magnification 400x (a), 200x (b, c)

8. Figure 3 shows the average score value described for each group of patients.

As shown in Fig. 3a, both AURKA intensity score and AURKA $^{+}$cells score were highly associated with platinumresponse. However, the AURKA total score demonstrated the highest capability to discriminate patients belonging to the two different platinum-sensitivity conditions $(p<0.001)$.

Furthermore, high levels of AURKA were also correlated to a worse overall survival ( $p=0.001$; HR 0.14) (Fig. 4).

\section{Discussion}

At present, platinum-based regimens represent the best therapeutic option for EOC patients. Taking into account that platinum-response is one of the most important prognostic factors for these patients, the identification of predictive biomarkers may be crucial in clinical practice.

In our study, we observed a statistically significant correlation between high level of AURKA in HGSOC specimens and platinum-resistance. Our results are in

Table 1 Distribution of AURKA in HGSOC patients. The average score value of AURKA is low in platinum sensitive patients and high in platinum resistant patients ${ }^{* *}(p<0.001)$

\begin{tabular}{|c|c|c|c|c|c|c|c|}
\hline \multicolumn{4}{|c|}{ Platinum Resistant } & \multicolumn{4}{|c|}{ Platinum Sensitive } \\
\hline Case & Age & Stage & $\begin{array}{c}\text { AURKA } \\
\text { IHC score }\end{array}$ & Case & Age & Stage & $\begin{array}{l}\text { AURKA } \\
\text { IHC score }\end{array}$ \\
\hline $1 R$ & 76 & IIC & $7(4+3)$ & 1S & 62 & IIIC & $2(1+1)$ \\
\hline $2 R$ & 68 & IIIB & $7(4+3)$ & $2 S$ & 71 & IIC & $4(2+2)$ \\
\hline $3 R$ & 51 & IIIC & $6(3+3)$ & $3 S$ & 66 & IV & $2(1+1)$ \\
\hline $4 \mathrm{R}$ & 52 & IV & $7(4+3)$ & $4 S$ & 72 & IV & $3(2+1)$ \\
\hline $5 R$ & 65 & IIIC & $5(3+2)$ & $5 S$ & 57 & IV & $2(1+1)$ \\
\hline $6 R$ & 67 & IIIB & $6(3+3)$ & $6 S$ & 68 & IIC & $3(2+1)$ \\
\hline $7 R$ & 64 & IIIC & $7(4+3)$ & 75 & 66 & IIB & $2(1+1)$ \\
\hline $8 \mathrm{R}$ & 80 & IV & $6(3+3)$ & $8 \mathrm{~S}$ & 59 & IIIA & $4(2+2)$ \\
\hline $9 R$ & 69 & IV & $8(5+3)$ & 9S & 70 & IIC & $3(2+1)$ \\
\hline $10 \mathrm{R}$ & 67 & IIIC & $6(3+3)$ & $10 \mathrm{~S}$ & 79 & IIIB & $4(3+1)$ \\
\hline $11 R$ & 48 & IIIB & $8(5+3)$ & $11 S$ & 53 & IIIB & $4(2+2)$ \\
\hline $12 \mathrm{R}$ & 57 & IIA & $7(4+3)$ & $12 S$ & 70 & IIIC & $2(1+1)$ \\
\hline $13 R$ & 64 & IIIB & $6(4+2)$ & $13 S$ & 74 & IIIC & $3(2+1)$ \\
\hline $14 R$ & 46 & IA & $6(3+3)$ & $14 \mathrm{~S}$ & 58 & IV & $4(2+2)$ \\
\hline $15 R$ & 71 & IIIB & $7(5+2)$ & $15 S$ & 61 & IV & $0(0+0)$ \\
\hline $16 R$ & 88 & IIIC & $3(2+1)$ & $16 S$ & 44 & IV & $4(2+2)$ \\
\hline $17 \mathrm{R}$ & 65 & IIIC & $3(2+1)$ & $17 \mathrm{~S}$ & 71 & IIIC & $6(4+2)$ \\
\hline $18 \mathrm{R}$ & 59 & IV & $7(4+3)$ & $18 \mathrm{~S}$ & 53 & IIIC & $4(3+1)$ \\
\hline \multirow[t]{4}{*}{$19 R$} & 70 & IIIC & $8(5+3)$ & $19 S$ & 59 & IIIC & $4(3+1)$ \\
\hline & & & & $20 \mathrm{~S}$ & 59 & IIIC & $3(2+1)$ \\
\hline & & & & $21 S$ & 44 & IIIC & $3(2+1)$ \\
\hline & & & & $22 \mathrm{~S}$ & 58 & IIIC & $5(3+2)$ \\
\hline
\end{tabular}




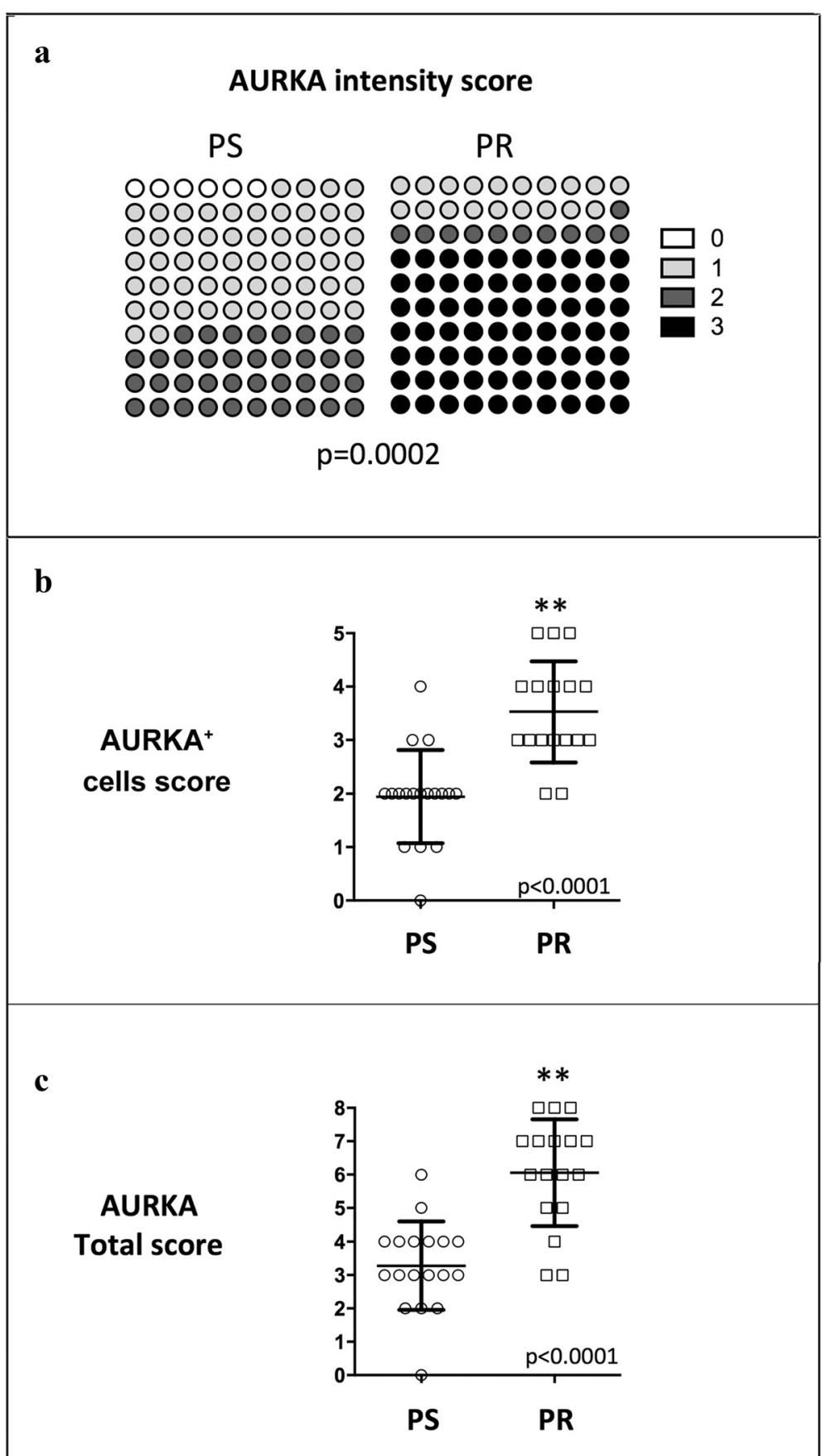

Fig. 3 Correlation of AURKA scores with platinum-response. A strong association between both Intensity (Panel a) and Cell percentage (Panel b) scores with platinum response is showed. Panel $\mathbf{c}$ reports the correlation between AURKA total score and platinum response

line with in vitro studies, demonstrating that overexpression of AURKA accounts for resistance to taxane and platinum agents [17, 18, 40, 41]. Additionally, recent reports show that cells depleted of AURKA are more sensitive to cisplatin-induced apoptosis, and elevated expression of Aurora kinase A antagonizes this response [42].
From a practical point of view, our series may be stratified into three different groups according to the score obtained and the platinum-status. All the patients with scores 6-8 were platinum-resistant, while those with scores $0-2$ were all platinum-sensitive. Therefore, we have determined two cut-off (score 2 and score 6) that seem to 


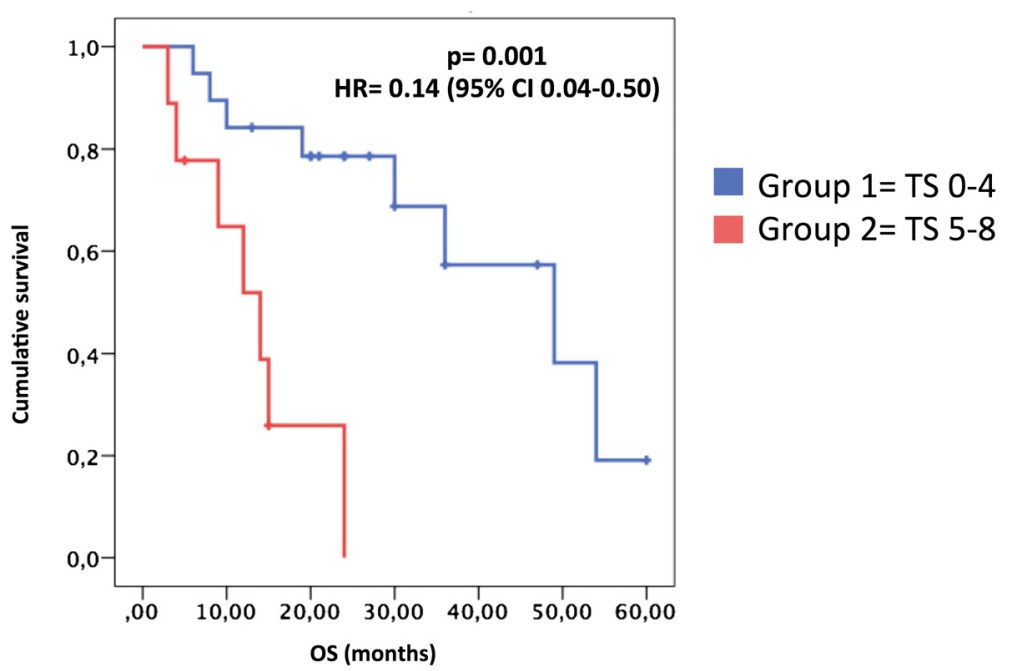

Fig. 4 Correlation of AURKA scores with survival. Kaplan Meier curves of EOC patients grouped according to high or low AURKA total score. TS: Total Score

be able to identify the patients responsiveness to platinum treatment from chemoresistant patients. Patients with intermediate score, between three and six presented contrasting outcomes. For these patients, a FISH-based approach or further molecular analyses should be recommended in order to deeply characterize and quantify the expression of AURKA and subsequently correlate it with outcome measures.

Taking into account the poor prognosis of platinumresistant patients, the routine use of this new biomarker could help clinicians in choosing the best frontline treatment. Indeed, by evaluating the AURKA pattern, chemoresistant patients in advanced stages could be easily identified, in order to prevent unnecessary severe side effects as well as to reduce treatment costs [41].

To the best of our knowledge, the expression and prognostic significance of AURKA in HGSOC has been poorly investigated. In 2007, Lessmann et al. suggested AURKA as a predictive marker in EOC. However, no data have been yet reported on its potential role in the prediction of response to platinum/taxane treatment [43].

The major limitations of our study is the low number of patients enrolled, the retrospective design and the lack of an independent validation series. Indeed, our work should be considered "hypothesis generating" and further prospective validation is eagerly awaited and is planned in the next future.

\section{Conclusion}

The reported findings suggest AURKA as a new tool to predict the clinical behavior of HGSOC. Particularly, these results suggest that AURKA may have a role both as predictor of platinum-resistance and prognostic factor. Indeed, in the era of personalized medicine, the availability of new predictive biomarkers is crucial for the selection of better treatment in the scenario of a continuum of care. Moreover our findings suggest that targeting AURKA may hold promise as a new therapeutic strategy in EOC management.

\section{Declaration}

The authors declare that the work described has not been published previously.

\section{Ethics approval and consent to participate}

Not applicable.

\section{Consent for publication}

Informed consents to participate in the study were obtained from participants.

\section{Availability of data and material}

The datasets supporting the conclusions of this article are included within the article.

\section{Additional file}

Additional file 1: Figure S1. Correlation of platinum sensitivity status with survival. Kaplan Meier curves of EOC patients grouped according to platinum sensitive (PS) or resistant (PR) disease. Patients with a platinum sensitive ovarian cancer presents a significant longer survival thus confirming the reliability of the sample. (JPG $182 \mathrm{~kb}$ )

\section{Abbreviations}

AURKA: Aurora Kinase A; DAB: 3, 3'-diaminobenzidine tetrahydrochloride; EOC: epithelial ovarian cancer; HGSOC: High-Grade Serous Ovarian Carcinoma; HR: hazard ratios; OS: overall survival; PR: platinum-resistant; PS: platinum-sensitive; RR: response rate. 


\section{Competing interests}

The authors declare that they have no competing interests.

\section{Authors' contributions}

$\mathrm{CM}$, designed the study and wrote the manuscript. NS, collected clinical data and performed statistical analysis. CB, collected clinical data and performed statistical analysis. CDM, collected data and performed immunohistochemistry analysis. AR, collected data and revised the manuscript. MM, performed the surgery and follow-up of patients. ADC, was responsible of the surgery and follow-up of the patients. SL, performed the analysis and interpretation of immunohistochemistry results. CC, performed immunohistochemistry analysis. IP, reviewed the literature and performed the statistical analysis. NM, performed the analysis of clinical data and immunohistochemical analysis. AS, was responsible of the oncologic management and follow-up of patients. PT and PT reviewed the study and the manuscript. TB, was involved in drafting the manuscript and given final approval of the version to be published. GD, designed the study and revised the manuscript. ADV, reviewed the literature and wrote the manuscript. All authors revised and approved the final draft of the manuscript.

\section{Acknowledgements}

None

\section{Funding}

None

\section{Author details}

'Department of Health Science, Pathology Unit, Magna Græcia University of Catanzaro, Medical School, Viale Europa, 88100 Catanzaro, Italy. ${ }^{2}$ Department of Experimental and Clinical Medicine, Medical Oncology, Magna Græcia University of Catanzaro, Medical School, Viale Europa, 88100 Catanzaro, Italy. ${ }^{3}$ Translational Medical Oncology Unit, Department of Experimental and Clinical Medicine, Magna Græcia University, Catanzaro, Italy. ${ }^{4}$ Department of Experimental and Clinical Medicine, Magna Græcia University, Catanzaro, Italy. ${ }^{5}$ Department of Medical and Surgical Sciences, Magna Græcia University, Catanzaro, Italy. ${ }^{6}$ Department of Mental and Physical Health and Preventive Medicine, Second University of Naples, Naples, Italy.

Received: 18 March 2016 Accepted: 5 May 2016

\section{Published online: 21 May 2016}

\section{References}

1. Siegel RL, Miller KD, Jemal A. Cancer statistics, 2015. CA Cancer J Clin. 2015; 65:5-29.

2. Jemal A, Bray F, Center MM, Ferlay J, Ward E, Forman D. Global cancer statistics. CA Cancer J Clin. 2011;61:69-90.

3. Seidman JD, Horkayne-Szakaly I, Haiba M, Boice CR, Kurman RJ, Ronnett BM. The histologic type and stage distribution of ovarian carcinomas of surface epithelial origin. Int J Gynecol Pathol. 2004:23:41-4.

4. Kobel M, Kalloger SE, Huntsman DG, Santos JL, Swenerton KD, Seidman JD, Gilks CB, Cheryl Brown Ovarian Cancer Outcomes Unit of the British Columbia Cancer Agency VBC. Differences in tumor type in low-stage versus high-stage ovarian carcinomas. Int J Gynecol Pathol. 2010;29:203-11.

5. Shih le M, Kurman RJ. Ovarian tumorigenesis: a proposed model based on morphological and molecular genetic analysis. Am J Pathol. 2004;164:1511-8.

6. Kuhn E, Wu RC, Guan B, Wu G, Zhang J, Wang Y, Song L, Yuan X, Wei L, Roden RB, et al. Identification of molecular pathway aberrations in uterine serous carcinoma by genome-wide analyses. J Natl Cancer Inst. 2012;104:1503-13.

7. Jonsson JM, Johansson I, Dominguez-Valentin M, Kimbung S, Jonsson M, Bonde JH, Kannisto P, Masback A, Malander S, Nilbert M, Hedenfalk I. Molecular subtyping of serous ovarian tumors reveals multiple connections to intrinsic breast cancer subtypes. PLoS One. 2014;9, e107643.

8. Gilks CB, Prat J. Ovarian carcinoma pathology and genetics: recent advances. Hum Pathol. 2009;40:1213-23.

9. Miller DS, Blessing JA, Krasner CN, Mannel RS, Hanjani P, Pearl ML, Waggoner SE, Boardman CH. Phase II evaluation of pemetrexed in the treatment of recurrent or persistent platinum-resistant ovarian or primary peritoneal carcinoma: a study of the Gynecologic Oncology Group. J Clin Oncol. 2009;27:2686-91.
10. Colombo N, Gore M. Treatment of recurrent ovarian cancer relapsing 6-12 months post platinum-based chemotherapy. Crit Rev Oncol Hematol. 2007;64:129-38

11. Staropoli N, Ciliberto D, Botta C, Fiorillo L, Grimaldi A, Lama S, Caraglia M, Salvino A, Tassone P, Tagliaferri P. Pegylated liposomal doxorubicin in the management of ovarian cancer:

a systematic review and metaanalysis of randomized trials. Cancer Biol Ther. 2014;15:707-20.

12. Staropoli N, Ciliberto D, Botta C, Fiorillo L, Gualtieri S, Salvino A, Tassone P, Tagliaferri P. A retrospective analysis of pegylated liposomal doxorubicin in ovarian cancer: do we still need it? J Ovarian Res. 2013;6:10.

13. Chien J, Kuang R, Landen C, Shridhar V. Platinum-sensitive recurrence in ovarian cancer: the role of tumor microenvironment. Front Oncol. 2013;3:251.

14. Colombo PE, Fabbro M, Theillet C, Bibeau F, Rouanet P, Ray-Coquard I. Sensitivity and resistance to treatment in the primary management of epithelial ovarian cancer. Crit Rev Oncol Hematol. 2014;89:207-16.

15. Zhang J, Li B, Yang Q, Zhang P, Wang H. Prognostic value of Aurora kinase A (AURKA) expression among solid tumor patients: a systematic review and meta-analysis. Jpn J Clin Oncol. 2015;45:629-36.

16. Umene K, Banno K, Kisu I, Yanokura M, Nogami Y, Tsuji K, Masuda K, Ueki A, Kobayashi Y, Yamagami W, et al. Aurora kinase inhibitors: Potential molecular-targeted drugs for gynecologic malignant tumors. Biomed Rep. 2013;1:335-40.

17. Hata T, Furukawa T, Sunamura M, Egawa S, Motoi F, Ohmura N, Marumoto T, Saya $H$, Horii A. RNA interference targeting aurora kinase a suppresses tumor growth and enhances the taxane chemosensitivity in human pancreatic cancer cells. Cancer Res. 2005;65:2899-905.

18. Anand S, Penrhyn-Lowe S, Venkitaraman AR. AURORA-A amplification overrides the mitotic spindle assembly checkpoint, inducing resistance to Taxol. Cancer Cell. 2003;3:51-62.

19. Carmena M, Earnshaw WC. The cellular geography of aurora kinases. Nat Rev Mol Cell Biol. 2003;4:842-54.

20. Fu J, Bian M, Jiang Q, Zhang C. Roles of Aurora kinases in mitosis and tumorigenesis. Mol Cancer Res. 2007;5:1-10.

21. Ewart-Toland A, Briassouli P, de Koning JP, Mao JH, Yuan J, Chan F, MacCarthy-Morrogh L, Ponder BA, Nagase H, Burn J, et al. Identification of Stk6/STK15 as a candidate low-penetrance tumor-susceptibility gene in mouse and human. Nat Genet. 2003;34:403-12.

22. Akkiz H, Bayram S, Bekar A, Akgollu E, Ozdil B. Relationship between functional polymorphism in the Aurora A gene and susceptibility of hepatocellular carcinoma. J Viral Hepat. 2010;17:668-74.

23. Cox DG, Hankinson SE, Hunter DJ. Polymorphisms of the AURKA (STK15/ Aurora Kinase) Gene and Breast Cancer Risk (United States). Cancer Causes Control. 2006;17:81-3.

24. Chen J, Li D, Wei C, Sen S, Killary AM, Amos Cl, Evans DB, Abbruzzese JL, Frazier ML. Aurora-A and p16 polymorphisms contribute to an earlier age at diagnosis of pancreatic cancer in Caucasians. Clin Cancer Res. 2007:13:3100-4

25. Ewart-Toland A, Dai Q, Gao YT, Nagase H, Dunlop MG, Farrington SM, Barnetson RA, Anton-Culver H, Peel D, Ziogas A, et al. Aurora-A/STK15 T + $91 \mathrm{~A}$ is a general low penetrance cancer susceptibility gene: a meta-analysis of multiple cancer types. Carcinogenesis. 2005;26:1368-73.

26. Ju H, Cho H, Kim YS, Kim WH, Ihm C, Noh SM, Kim JB, Hahn DS, Choi BY, Kang C. Functional polymorphism $57 \mathrm{Val}>$ lle of aurora kinase A associated with increased risk of gastric cancer progression. Cancer Lett. 2006;242:273-9.

27. Kimura MT, Mori T, Conroy J, Nowak NJ, Satomi S, Tamai K, Nagase H. Two functional coding single nucleotide polymorphisms in STK15 (Aurora-A) coordinately increase esophageal cancer risk. Cancer Res. 2005;65:3548-54

28. Matarasso N, Bar-Shira A, Rozovski U, Rosner S, Orr-Urtreger A. Functional analysis of the Aurora Kinase A lle31 allelic variant in human prostate. Neoplasia. 2007:9:707-15.

29. Zou Z, Yuan Z, Zhang Q, Long Z, Chen J, Tang Z, Zhu Y, Chen S, Xu J, Yan $M$, et al. Aurora kinase A inhibition-induced autophagy triggers drug resistance in breast cancer cells. Autophagy. 2012;8:1798-810.

30. Karthigeyan D, Prasad SB, Shandilya J, Agrawal S, Kundu TK. Biology of Aurora A kinase: implications in cancer manifestation and therapy. Med Res Rev. 2011;31:757-93.

31. Chen SS, Chang PC, Cheng YW, Tang FM, Lin YS. Suppression of the STK15 oncogenic activity requires a transactivation-independent p53 function. EMBO J. 2002;21:4491-9. 
32. Ouchi M, Fujiuchi N, Sasai K, Katayama H, Minamishima YA, Ongusaha PP, Deng C, Sen S, Lee SW, Ouchi T. BRCA1 phosphorylation by Aurora-A in the regulation of G2 to M transition. J Biol Chem. 2004;279:19643-8.

33. Yang H, Ou CC, Feldman Rl, Nicosia SV, Kruk PA, Cheng JQ. Aurora-A kinase regulates telomerase activity through c-Myc in human ovarian and breast epithelial cells. Cancer Res. 2004;64:463-7.

34. Dar AA, Belkhiri A, El-Rifai W. The aurora kinase A regulates GSK-3beta in gastric cancer cells. Oncogene. 2009;28:866-75.

35. Gritsko TM, Coppola D, Paciga JE, Yang L, Sun M, Shelley SA, Fiorica JV, Nicosia SV, Cheng JQ. Activation and overexpression of centrosome kinase BTAK/Aurora-A in human ovarian cancer. Clin Cancer Res. 2003:9:1420-6.

36. Yu CT, Hsu JM, Lee YC, Tsou AP, Chou CK, Huang CY. Phosphorylation and stabilization of HURP by Aurora-A: implication of HURP as a transforming target of Aurora-A. Mol Cell Biol. 2005;25:5789-800.

37. Allred DC, Harvey JM, Berardo M, Clark GM. Prognostic and predictive factors in breast cancer by immunohistochemical analysis. Mod Pathol. 1998:11:155-68.

38. Mohsin SK, Weiss H, Havighurst T, Clark GM, Berardo M, Roanh le D, To TV, Qian Z, Love RR, Allred DC. Progesterone receptor by immunohistochemistry and clinical outcome in breast cancer: a validation study. Mod Pathol. 2004;17:1545-54.

39. Henderson-Jackson EB, Helm J, Strosberg J, Nasir NA, Yeatman TJ, Kvols LK Coppola D, Nasir A. Palladin is a marker of liver metastasis in primary pancreatic endocrine carcinomas. Anticancer Res. 2011;31:2957-62.

40. Chung CM, Man C, Jin Y, Jin C, Guan XY, Wang Q, Wan TS, Cheung AL, Tsao SW. Amplification and overexpression of aurora kinase A (AURKA) in immortalized human ovarian epithelial (HOSE) cells. Mol Carcinog. 2005:43:165-74.

41. Salani R. Neoadjuvant chemotherapy vs primary debulking surgery for advanced ovarian cancer. What is the debate regarding the ideal treatment: approach? age? or cost? Am J Obstet Gynecol. 2015;212:695-6.

42. Katayama H, Sasai K, Kawai H, Yuan ZM, Bondaruk J, Suzuki F, Fujii S, Arlinghaus RB, Czerniak BA, Sen S. Phosphorylation by aurora kinase A induces Mdm2-mediated destabilization and inhibition of p53. Nat Genet. 2004;36:55-62.

43. Lessmann E, Ngo M, Leitges M, Minguet S, Ridgway ND, Huber M. Oxysterol-binding protein-related protein (ORP) 9 is a PDK-2 substrate and regulates Akt phosphorylation. Cell Signal. 2007;19:384-92.

\section{Submit your next manuscript to BioMed Central and we will help you at every step:}

- We accept pre-submission inquiries

- Our selector tool helps you to find the most relevant journal

- We provide round the clock customer support

- Convenient online submission

- Thorough peer review

- Inclusion in PubMed and all major indexing services

- Maximum visibility for your research

Submit your manuscript at www biomedcentral.com/submit

) Biomed Central 